\title{
PSYCHICAL SELECTION: EXPRESSION AND IMPRESSION
}

\author{
By C. LLOYD MORGAN.
}

1. Introductory (pp. 206, 207).

2. Relation of Expression to Impression (pp. 207-209).

3. Imitation. Behaviour with and without Intention (pp. 209, 210).

4. Similar Expression with different Impression (pp. 210, 211).

5. Similar Expression in different situations (pp. 211, 212).

6. Behaviour in 'Courtship.' Is it primarily intentional? (p. 213).

7. Two sub-classes of secondary sexual Characters. An example from Insect life (pp. 213-215).

8. A 'taste for the beautiful' (pp. 215, 216).

9. The stress on 'recognition' (pp. 216-218).

10. The Expressive Behaviour of the Male (pp. 218-221).

11. The coyness of the Flemale (pp. 221, 222).

12. Conclusion (pp. 222-224).

1.

Whatever may be said for and against the hypothesis of natural selection, this is not the place to defend it. Properly safeguarded I for one accept it whole-heartedly. Here I am concerned with psychical selection. In some sense of the phrase it has unquestionably been a factor in evolutionary progress. I propose then to discuss what seems to be its chief relational feature. This will involve a reconsideration of some of the data afforded by sexual selection. But for our present purpose, and in this Journal, the emphasis falls on psychological factors. And since psychology does not deal only with mental processes in man, since, too, salient examples of that which is to be considered are afforded in the life of birds, most of the illustrations will be taken from their behaviour and what seems to be implied thereby.

Some reference will be made to the emotional qualification of consciousness or, as I prefer to say, of enjoyment. Fully realising the great value and importance of Mr Shand's treatment of the emotions as conational complexes definable by their ends, I here regard them as affects, describable only as what they feel like, though the concrete 
instances of mental process in which their presence may be detected are no doubt cognitive and conative as well as affective. I am not here concerned, however, to distinguish their several qualities, save incidentally in a quite perfunctory way. This does not fall within my picture. But a more general question is pertinent. What is the good of emotion-not of this or that quality of affect-but just of emotion as such? What utility can be assigned to it? For our present purpose, without staying to defend the position, I define emotion as supernormal enjoyment, positive or negative. And the good of it-its utility from the evolutionary point of view-is to modify the behaviour of the organism with whose functional activities such super-normal enjoyment is correlated. Behaviour is generally enhanced and rendered more strenuous; sometimes its level of vigour is depressed; and occasionally, in abnormal cases, its effective integration is interfered with; but in these last cases its biological end is defeated. It need hardly be said that there is in this broad view nothing to preclude differentiation of behaviour in accordance with the specific quality of the emotional affect in correlation, let us say, with the 'hormonic' balance in the organism.

A further introductory sentence must be added. I use the word 'instinctive' as adjectival to behaviour (or to a disposition to behave) in so far as such behaviour has not been learnt in the course of individua] life. It is, however, in this usage, very often only an instinctive factor, which, though inseparable, is distinguishable, under analysis, from the acquired factor due to individual learning and profiting by experience. I think that in reference to behaviour, and its correlated enjoyment, this usage may be retained without prejudice to the different usages of Prof. McDougall, of Dr Drever, and of others whose universe of discourse is in one sense narrower, and in another sense wider, than that of the following discussion; narrower in so far as it is mainly concerned with instinct in man; wider in so far as it is applicable to more than behaviour with its specifically correlated enjoyment.

2.

In the life of birds the behaviour is apparently similar under different circumstances-for example when intruders of the same or of allied species enter the breeding territory, when so-called courtship is in progress, and when the young are disturbed. In each situation the bird appears to be in a state of excitement which we interpret as emptional; but the emotional qualification of enjoyment seems to us to be anger in the first case; to be that which accompanies strongly felt sex-hunger 
in the second case; and to be something of the nature of distress in the third case. What we have to lay stress upon is the similarity in the type and intensity of the response at different emotional periods. Here the question of biological value naturally arises. Is the similar behaviour contributory either to race-maintenance, or to self-preservation, or to both, under all the different circumstances in which it is observed? Those who assert that only that structure or that behaviour which has utility can escape elimination in the struggle for existence, seem bound to contend that the behaviour must be useful at some period of life; but there seems no reason why we should reject the hypothesis that the same type of behaviour may be useful in different ways in different situations. As Mr Eliot Howard says in his British Warblers: "If it can be shown that there is a strong probability of some specific type of behaviour serving a double or a treble purpose, so much the more reason is there for its survival. The reactions that we meet with in bird life may thus be said to have developed firstly as a means for arousing the requisite amount of pairing hunger in the female, secondly as a warning to intruders; and thirdly as a protection for the helpless offspring. Clearly everything centres round the strength of the probability in each case.".

In the third case to which Mr Howard here refers, the protection of the helpless offspring is afforded indirectly. The behaviour of the parents is such as to draw to themselves the attention of intruders, and thus to divert attention from the young, which are thus preserved from injury. Now we may speak of the behaviour in all three situations as an expression of a disposition which is emotionally toned. And in all three situations the suggested utility of the expression-that utility of which we seek evidence-arises from the impression which is produced thereby-in the first by arousing the requisite pairing hunger; in the second as a warning to intruders; and in the third by diverting attention from the helpless young. I propose, therefore, to use the word 'expression' for that which is correlative to 'impression,' on the understanding that such impression is normally provocative of behaviour in the organism which receives it. On these terms expression is a sub-species of behaviour differentiated from other modes of behaviour in that its utility lies in the impression it produces on some other organism; while the impression is a sub-species of presentation differing from other presentations in that what is presented is expressive behaviour on the part of some other organism. If this usage of the words be accepted, the points for emphasis are (1) that 
what is apparently the same expression is expressive of different emotional states, and, further, (2) that the impression produced is different in different situations. On the thorough-going doctrine of utility there must be some biological value in each situation. But not all behaviour is expressive in the sense suggested. It seems that, in bird life, there are many activities which are not expressive on these terms. Birds are very active in the early hours of the day, especially during the breeding season. But how much of their procedure is expressive, in the sense that the utility, or even part of the utility, of what they do lies in the impression it produces on another bird, or animal, and, through that impression, influences its behaviour? Not all certainly; still, some of it is thus expressive and does produce an impression; and that is what we are here concerned with.

3.

Passing reference to imitation is here in place. Setting on one side what Prof. Mark Baldwin speaks of as 'self-imitation,' it takes at least two to constitute an imitative situation. In such a situation there is behaviour on the part of $A$; and this behaviour is expressive in our sense in so far as there is an answering impression received by $B$; and the behaviour of $B$ is imitative in so far as it resembles the expressive behaviour of $A$. Imitation is therefore a specialised case of the relation of expression to impression. Since, however, there are those who contend that imitation, sensu stricto, implies intention to imitate, it should be understood that I here use the word as inclusive even of what the biologist may term 'mimetic' behaviour where intention is absent. Are there then cases of imitation in a broad sense which are to be regarded as instinctive? From my point of view there can be no doubt as to the answer. There are forms of imitation in this broad sense which have not to be learnt but just come by nature.

Now perhaps it will be said that if we rule out intention we thereby place such so-called imitation altogether outside the universe of psychical regard. But is this so if the impression is itself psychical in its nature? I assume that as an enjoyed presentation it is so. And I urge that, if so, the expression which gets its value as such in relation to the psychical impression is thereby drawn within the field of psychological regard. That is why I lay stress on expression as, for our purpose, to be taken in its relation to impression. They are correlative terms in one field of relatedness. None the less the distinction between behaving with intention and behaving without intention is important. It must be steadily 
borne in mind. And this is the more necessary because so much of our own behaviour is in relation to foreseen ends, and because the consequences of our own acts are so often quite definitely and deliberately intended. But even with us surely not always. And in the case of animals purely instinctive acts (if such there be) and much of their behaviour, in so far as instinctive and unlearnt by the individual performer, afford, as I think, no evidence of an end in view such as intention involves. Professor Stout would say that a very vague and indefinite end in view is always present. Let it go at that. Practically (I do not say theoretically) there is little difference between what I mean by absence of intention and what he claims as present in so nebulous a form.

We must realise then that, in some measure in human life, and probably in far larger measure in animal life there may be expression which produces impression in the complete absence (for purposes of practical interpretation) of any intention to produce that impression; and that this is especially the case in so far as instinctive factors of behaviour are concerned. If it be granted therefore that apparently similar behaviour at one time warns off an intruder into the territory, at another time stimulates the pairing hunger of the hen bird, and at yet another time attracts the attention of an animal that too closely approaches the young, there need be no intention to warn, or to win the mate, or to draw off from the offspring, still less, in the last case, to delude by simulating helplessness. On my view there is no such intention so far as the behaviour is instinctive, though it may be present so far as acquired experience is co-operant. So too the impression received need be no more than provocative of responsive behaviour which the recipient feels like carrying out.

4.

Let us, then, take expression and impression as correlative; and let us assume that for behaviour to be expressive there need be no intention to make an impression on, say, some other bird, and that behaviour may instinctively be the outcome of impression without any intention so to behave. We may now ask how we can account for the fact that, so far as observation goes, the same or very similar expression in behaviour seems on different occasions to produce a different impression, or at any rate one which leads to very different behaviour on the part of the recipient. I do not think this presents much difficulty. In the first place the observations which Mr Howard describes are made on adult birds, and, in them, what we speak of as the impression carries 
meaning which has been acquired in the course of previous experience. Indeed it is only with some difficulty that we can realise that there may be impressions, and other presentations in naive awareness, which have not put on the vesture of acquired meaning. And so far as such meaning is present, there is no difficulty whatever in understanding how closely similar impressions may be differentiated on different occasions. Let us however consider what is actually presented, say to vision, on the several occasions. Is it so similar as at first sight it may seem? By fixing our attention on the expressive attitudes and movements we regard them in isolation from their context. But as they are presented to the recipient of the impression they are nowise thus isolated. They are set in the context of the situation as a whole. More than we readily realise the animal, like the little child, is responsive rather to the total presented situation than to the details-even the salient details-which we, for the purposes of our thought, distinguish and isolate. We concentrate attention on the similarity of behaviour because that is what we seek to interpret; and yet we see clearly enough that in each of the three cases to which Mr Howard refers, the circumstances differ notwithstanding the similarity of expressive behaviour in their midst. The situations are clearly differentiated for our observation. Why should not the bird, after his naĩver fashion, feel this difference and act accordingly? Why should not the context play its part in determining his behaviour? We must remember, too, that living through, and behaving in the midst of, a given situation begets an attitude of mind, a progressive differentiation of enjoyment, in relation to just that situation. The outlook of the bird is brought into harmony with that upon which he looks out. Not only therefore is there difference in the world context in which the expression finds its place, there is difference also in the mind context in which the impression finds its place. During the period of so-called courtship the male bird, and probably the female too, are, very markedly, as it seems, under the influence of sex-hunger, and we may well suppose that specialised interest colours the whole situation and gives at that time special meaning to expressive behaviour, which, seen at other times, would carry a different meaning.

5.

But how are we to account for the similarity of expression in different situations? Why should there be much the same behaviour when another male enters the breeding territory, when mating is in progress, and when the young are disturbed? In the first place it should be re- 
membered that the modes of behaviour now in question are chiefly in evidence during the period when dispositions subsidiary to race-maintenance find expression in modes of action common to this period under the physiological influence of the internal secretions of the group of related glands in the organic sex-complex. If this common expression have diverse utility in different situations, like factors therein would be emphasized. The whole period is one of unusual excitement-i.e. emotion as super-normal-and it may be that the readiest outlet of the motor effects of this excitement is along certain predetermined channels. One is here reminded of Herbert Spencer's doctrine that an overflow of 'nervous force' takes first the most 'habitual' routes. And one knows that in the case he discussed in advocating this view ${ }^{1}$ laughter may be the outcome of very different kinds of emotional excitement, often, as we commonly say, of mere high-strung nervous tension. It may be, therefore, that the similar behaviour in different situations is an index of a general type of excitement under a ruling disposition, and that we must, and practically do, infer the specific quality of the emotional affect rather from the context of the behaviour than from the behaviour itself. There may, too, be subtle differences which our powers of observation are not sufficiently delicate to enable us readily to distinguishdifferences analogous to those between the genial laugh of good fellowship, the laugh of exultation over a fallen enemy, and the laugh of irritation when, say, a golfing opponent has his usual persistent and undeserved good luck. These differences we learn to appreciate because we too are human folk and grasp the nuances of the situation. May there not be differences which birds sense better than we do, just because they are birds? Such modes of expression as we are considering, in their relation to impressions received, whether they are really alike on different occasions, or really slightly diverse and only apparently the same, betoken, as has been said, periods of excitement. That excitement should find an outlet in vigorous behaviour has biological value and hence utility in a broad sense. It is a relief from tension and strain which might otherwise be harmful to the organism. If there be also specialised utility in affording an impression which stimulates another bird to behaviour appropriate to the situation, there do not seem to be insuperable difficulties which preclude an adequate interpretation of the facts. 
6.

Let us now consider in further detail the bird's behaviour during the period of so-called courtship. It may be well first to say why I speak of so-called courtship. I take it that the word 'courtship' may naturally be held to imply intention on the part of the male so to act-so to sing, for example, or so to display his plumage-as to make himself attractive to the hen-bird he 'seeks to win' as his mate. Now of course such intention may be present. There may be in the mind of the male something of this sort: "By such and such expression an impression will be produced; and the production of this impression will contribute to the end I have in view." It may be vaguer than this-so vague that one can hardly put it in words; he may just realise in some dim but sufficient way that what he does has its effect and intends to do it for the sake of this effect. On the other hand it may be urged that what is necessary for an interpretation of the observed facts is less even than this. All that is required, on this view, is that, in accordance with his disposition at the time, the male feels like behaving in certain ways; that this behaviour does produce a stimulating impression; and that, on the receipt of this impression, the hen-bird, in accordance with her disposition at the time, feels like mating with him. We will provisionally assume that only this minimum is present so far as the instinctive factors in behaviour are concerned.

It may be said that no act in adult life is purely instinctive. When the bird has reached the age of 'courtship' there is always in addition to, and intimately combined with, the instinctive and unlearnt factor in behaviour, some legacy from the lessons which have already been learnt. That is so; and it is just this which renders interpretation peculiarly difficult. My point is that, so far as we can get at the facts by observation, there is in the male bird's procedure much that is seemingly unlearnt-much that seems just to come in presence of the 'courtship' situation when first it is presented. And I urge that, so far as this unlearnt part is concerned, intention so to act as to attain results of which there has been no prior experience, is presumably absent.

\section{7.}

We must now come to still closer quarters with some of the phenomena connected with the life of birds in the period of 'courtship.' In the Second Part of his great work on The Descent of Man, Darwin very fully discusses the evidence for his hypothesis of sexual selection 
as a factor in evolution. How does he differentiate it from natural selection or, as he sometimes puts it, from other forms of natural selection? It depends, he says, "on the advantage which certain individuals have over others of the same sex and species solely in respect of reproduction." This advantage has specialised biological value to the end of mating, and hence there have been developed secondary sexual characters which in their present form are in part due to this selection.

Now it is clear that the secondary characters developed, as Darwin claims, through sexual selection, fall within two different sub-classes; (1) those which are not primarily dependent on the impression they make on the mate; (2) those which are thus dependent since they allure or excite an individual of the other sex. Those in the first category are of advantage in the struggle to secure a mate; but they are not necessarily of advantage through any appeal they make to that mate. It is not through her preference under psychical selection, that the best fighter wins. She may also prefer the winner; but she must often yield to the victor whether she prefers him to others or not. She must often yield to him who can capture and hold her. She is just a prize to the strong, and has, so to speak, no voice in the matter. But under the second category the advantage lies with the possessor of those organs and structures, used to the best effect, which so allure or excite the female as not merely to force but to induce her to mate.

Since from the point of view here taken the whole matter turns on the relation of expression to impression it may be well to consider briefiy a simple but in some respects typical example in insect life. "The female of the Emperor moth (Saturnia carpini) is so eagerly sought by the males that when a virgin female is taken into a favourable locality, the collector is soon surrounded by troops of males which have been guided by a marvellously delicate sense of smell residing in their branching antennae. So delicate is the sense that the female is recognized perhaps miles away, and recognized as a virgin ${ }^{2}$." Now here the scent emitted by the female is a form of expression which produces a presentative impression on the males through receptors in the specially developed antennae. And there seems little doubt that the biological value of expression and impression here centres in, if it be not exclusively related to, reproduction. If this be so, the possession of specialised antennae may fairly be regarded as a secondary sexual character in the male. It will, no doubt, be said that there is here no evidence of preference on the part of the female; she does not select the male with the most

1 p. 322.

2 Poulton, Colours of Animals, p. 288. 
branching antennae. Still the case does fall under Darwin's principle as stated by him; and it does fall under the second category, for it involves alluring and exciting an individual of the other sex. Now let us suppose that, of two females, one produced the expressive scent in greater abundance than the other. That one would have a greater and more far-reaching effect. Some distant male, perhaps with better developed antennae than others, would receive an impression from the one female and not from the other, or perhaps a stronger impression from the one than from the other. May we say that if he flies to the one and not the other he chooses her? And can we say that in any valid sense she chooses him? Some will say: most certainly not. Choice is choice; and this is not choice. It is simply behaving under the stimulating influence of what is assumed to be the stronger impression. Yes! And that, I venture to suggest, is just what Darwin meant (even in the much more complex cases of bird-life) by speaking of the females as 'unconsciously preferring' certain males which most strongly excite them. "It is not probable," he says, "that she consciously deliberates; but she is most excited or attracted by the most beautiful, or melodious or gallant males.". One must remember that at our human level of mental development, choice is for the most part purposeful. As we commonly use the word there is nearly always implied a foreseen end for the sake of which the choice is made. At the much lower stage of mental development we are trying to read ourselves into-with difficulty since we must leave so much of ourselves out of account - at this stage what we are forced by the exigencies of language, fashioned to deal with human affairs, to speak of as choice or preference, may be much more naivve - so naive indeed as to be reduced to the level of the relation between adequate stimulation and adaptive response, if, but only if, we deliberately turn our gaze away from the correlated psychical aspect.

8.

Another verbal question-which like the others is really more than merely verbal-calls for passing comment; and then we can proceed on our way. In many passages Darwin speaks of a 'taste for the beautiful,' and uses the word 'aesthetic.' Thus he says " $O n$ the whole birds appear to be the most aesthetic of all animals, excepting of course man, and they have nearly the same taste for the beautiful as we have.". In what sense are we to understand 'taste'? The pilfering blackbird seems to have nearly the same taste for ripe fruit that we have. Is one

$$
{ }^{1} \text { p. } 643 .
$$


misunderstanding Darwin if one supposes that he used the phrase 'taste for the beautiful' in an analogous sense? I take it that Darwin did not wish to raise subtle questions, but to indicate fairly obvious inferences from what may be observed as interpreted in the light of his hypothesis. Look up the word 'aesthetic' in some current dictionary. Chamber's Twentieth Century Dictionary lies at hand. There I find, $s u b$. verb. "the feeling of beauty in objects; the principles of taste and of art; the philosophy of the fine arts." Which of these, thus or otherwise formulated, did Darwin mean? Surely, I venture to suggest, the first. What does the bird know of the principles of taste and of art? What of the philosophy of the fine arts? But I see no reason why we should not credit the Peahen, when the Peacock erects and spreads his splendid tail-coverts, with a qualification of enjoyment analogous to that which we too experience on sight of him, so long as we leave it at that and do not begin to discourse on aesthetic values, beauty for beauty's sake, and the rest. I may no doubt be reading out of Darwin part of what he really meant. Or it may be said that $I$ am reading into him my own views. But he does seem to safeguard his position in many passages in just the way I venture to suggest. Take for example this one. "I refer only," he says, "to the pleasure given by certain colours, forms and sounds, which may fairly be called a sense of the beautiful. With cultivated men such sensations are, however, intimately associated with complex ideas and trains of thought. When we behold a male bird elaborately displaying his graceful plumes, or splendid colours before the female, whilst other birds, not thus decorated, make no such display, it is impossible to doubt that she admires the beauty of her male partner1." For the present it is enough to lay stress on some differentiating character of the presentation which leads to response. It is this which seems to be really essential. There is differentiation in expression; this produces differentiated impression; and this again leads to a responsive act. When this expression evokes response, while that does not, we infer from the response that the female 'chooses' this male in preference to that one. But the observed facts may be interpreted on the supposition that this as expression affords an adequate impression while that does not; and that true choice with an end in view is absent.

9.

Let us revert for a moment to the Emperor moth. Prof. Poulton says, in the passage I quoted above, that so delicate is the sense of smell ${ }^{1}$ p. 140. 
in the male that the female is recognized perhaps miles away and recognized as a virgin. This use of the word 'recognized' is quite common among naturalists. But this recognition is not that the nature of which is discussed by psychologists. The latter is generally held to imply prior cognition in the course of individual life. All that is implied in what is sometimes called instinctive recognition is such impression as shall lead to responsive behaviour.

It is well known that Wallace was unable to accept sexual selection. And it is well known how much stress he laid on 'recognition marks.' "Among birds," he says, "these recognition marks are especially numerous and suggestive. Species which inhabit open districts are usually protectively coloured; but they generally possess some distinctive markings for the purpose of being easily recognized by their kind, both when at rest and during flight1." "Among insects the principle of distinctive coloration for recognition has probably been at work in the production of the wonderful variety of colour and marking we find everywhere, more especially among the butterflies and moths; and here its chief function may have been to secure the pairing together of individuals of the same species"." He speaks of "the various sounds and odours which are peculiar to the male, and which serve as a call to the female or as an indication of his presence. These are evidently a valuable addition to the means of recognition of the two sexes;... and thus the clearness, loudness, and individuality of the song becomes a useful character, and therefore the subject of natural selection ${ }^{3}$." Now recognition marks, call notes, and song, are, in our terminology, modes of expression; and Wallace's contention turns upon the claim, not only that they give rise to impression, but that, under natural selection, their very existence as such depends upon this impression-otherwise how can they be regarded as recognition marks evolved to this very end? But they are useful to each species "in relation to the most important function of their lives" "-that of reproduction. And it is just in view of their relation to this function that Darwin places them in the category of sexual selection. It is in virtue of this that recognition marks to the end of pairing are differentiated from warning colouration to the end of survival-also the outcome of the relation between expression and impression. But Wallace went even further on his way with Darwin than I have yet indicated. "Anyone," he says, "who reads these most interesting chapters [of Darwin's] will admit that the fact of display is demonstrated; and it may also be admitted, as highly probable, that
1 Darwinism, p. 222.
2 p. 226.
3 pp. 283, 284.
4 p. 285. 
the female is pleased or excited by the display." That seems to give Darwin pretty nearly all that he claims.

I have sought to emphasize the measure of harmony that may be found in Darwin and Wallace in the light of the relation which obtains between expression and impression. The point of interest to the psychologist is that for both certain features of structure or behaviour appeal to the mind and that in the absence of this appeal these features would not be what they are and as they are. Their evolution depends on a psychical factor-on some impression which they produce. Regarding then expression as correlative to impression, it seems that both the biological and the psychological value of expression is dependent on the psychical factor I deal with under the name 'impression.'

The further biological problems do not here concern us. Wallace was not satisfied that differential appeal of expression through the impression it produces suffices to enable us adequately to interpret the origin of secondary sexual characters. That may well be so. But Darwin dealt rather with the selection than the origin of these characters in the sense in which Wallace discussed the matter. These problems are not in our present picture. This however may be added. Wallace was unable to believe "that all the females of a species, or a great majority of them, over a wide area of country, and for many successive generations, prefer exactly the same modification of the colour or ornament ${ }^{1}$." But he seems to have found no difficulty in believing that all the members of a species recognize the same modification of colour or of ornament. But recognition marks imply differential impression and differential response no less than secondary sexual characters.

10.

Now so far as the response is instinctive there is, on our interpretation, no intentional or deliberate choice on the part of the female. But what about the behaviour of the male? Few would be prepared to contend that beautiful plumage is an intentional expression on the part of its possessor. Indeed it may be said that only by an extended use of the word can it thus be spoken of as an expression. Still it must be remembered that the word is here used as correlative to an impression produced, and in this sense the extension of usage is justifiable. If once we disabuse our thought of the idea that expression must necessarily be intentional, there is no reason why the brilliant plumage of birds, the mimetic or warning colouration of insects, the nectar, scent, and 
conspicuous hues of flowers, should not be regarded as expressive, in so far as they lead to impressions received by sentient organisms, and in so far as the expression has in some manner been evolved in relation to the impression produced and the behaviour which results therefrom. What we may speak of as structural expression, then, is not commonly regarded as, in any degree, intended by its possessor. When, however, we pass to 'display' in behaviour the presence of intention is generally assumed. It is indeed this assumed presence of intention which has led to the popular emphasis on the courtship of animals.

One who differs from Darwin in his interpretation of animal life, does so at his peril. In this matter of display Darwin spoke with no uncertain note. "When we behold two males fighting for the possession of the female; or several male birds displaying their gorgeous plumage, and performing the strangest antics before an assembled body of females, we cannot doubt that, though led by instinct, they know what they are about, and consciously exert their mental and bodily powers ${ }^{1}$." The males "sedulously display their charms before the females"." They "endeavour to charm or excite their mates by love-notes, songs, and antics"." They "display their fine plumage and other ornaments with so much care before the females." "Sufficient facts have now been given to show with what care male birds display their various charms, and this they do with the utmost skill. While preening their feathers they have frequent opportunities for admiring themselves, and of studying how best to exhibit their beauty. But as all the males of the same species display themselves in exactly the same manner, it appears that actions, at first perhaps intentional have become instinctive."." "Hence we may conclude that it is the object of the male to induce the female to pair with him, and for this purpose he tries to excite or charm her in various ways; and this is the opinion of all those who have carefully studied the habits of living birds."."

It is noteworthy that Darwin was generally careful to qualify his allusions to preference on the part of the females by using such a phrase as "prefer, or are unconsciously excited by the more beautiful males?". But with regard to the behaviour of the male he says roundly, on the same page, that "they display their colours with elaborate care and to the best effect." Still in one of the passages $I$ have quoted he seems ready to admit that in so far as instinctive, the behaviour is no longer intentional. And we have on the other side the passage in which it is

$$
\begin{aligned}
& 1 \text { p. } 325 . \quad \text { p. } 341 . \quad \text { p. } 561 . \quad \text { p. } 629 \text {; cf. pp. } 600,672 . \\
& \text { 5. 612. p. 616. } 757 .
\end{aligned}
$$


suggested that the male birds have opportunities, while preening their feathers, for admiring themselves, and for studying how best to exhibit their beauty. If this suggestion be accepted, the behaviour which is the outcome of this study is clearly so far learnt; data for the most effective manner of display are intelligently acquired. I cannot accept the suggestion even from Darwin. If we grant that the male engaged in the instinctive business of preening, is also admiring his fine feathers, what he sees in detail is very different from what the female will see when she views him as a whole from some distance. I regard it as extremely improbable that the male bird realises that what thus, $e x$ hypothesi, pleases him in detail, will produce, under quite different circumstances, so favourable an impression on his desired mate as to induce her to accept him. I am unable to water down what is supposed to pass through his mind to much less, in essentials, than this; and this I think is quite beyond his powers of inference.

I submit that the elaborate display, executed in substantially the same manner by all the males of the same species, may fairly be regarded, complex as it undoubtedly is, as quite unintentional. Behaviour is no doubt in delicate harmony with ornamentation. Darwin compares the plumage and the display of the Peacock and the Peacock Pheasant1. The arrangement of the ocelli is such that effective sensory presentation involves 'display,' in the one case when the male stands in front of the female, erects and expands the tail-coverts, and at the same time 'shows off' his rich blue throat and breast; and in the other case when he stands obliquely to the female lowering the expanded wing on the near side and raising that on the far side. In this attitude, the tail-feathers being also expanded obliquely, "the ocelli over the whole body are exposed before the admiring female in one grand bespangled expanse." By such expression is an adequate impression produced. If, with Wallace, we regard the origin and the special character of the ornamentation as independent of psychical selection, are we to regard also its specific manner of display as independent of such selection? If, as those who deny even 'unconscious preference' on the part of the female must urge, the so-called display produces no impression that leads to response, how are we to account for the differentiated manner of display in this species and in that? If on the other hand it be intelligently learnt in the course of individual life, to subserve the foreseen end, is there a satisfactory observational basis on which is founded the inference that such a process of learning does take place? To revert to Darwin's p. 605. 
suggestion that male birds are observed to preen their feathers. Is it likely that the Peacock or the Peacock Pheasant, in preening his feathers and admiring the ocelli thereon, reaches the conclusion that, as seen from some distance by the female, this mode of behaviour will display most effectively the specific ornamentation in the one case, and that in the other? Moreover it does not seem that the males of different species have to learn how to display their plumage to best advantage; this appears to come by nature. In other words the form of the behaviour as a whole appears, on the evidence, to be instinctive.

\section{1.}

Suppose, then, we regard it as a tenable view that the unlearnt basis of display is primarily instinctive, or in modern phrase a function of the unconscious; and suppose we regard the expressive display as giving rise to impressions on the part of the female; what then? How does the business work? "The courtship of animals," said Darwin, "is by no means so simple and short an affair as might be thought 1 "; and again, "the courtship is, in many instances, a prolonged affair $2 . "$ Furthermore "as the illustrious Hunter long ago observed," the female "generally requires to be courted; she is coy, and may often be seen endeavouring for a long time to escape from the male." Here we have, in the germ, the interpretation so ably developed by Gross in his Play of Animals. We must, however, be content to deal, and that briefly, with the root idea, which is that the coldness or coyness of the female (which surely involves a psychical factor) is only overcome by the adequate effect of strong expression on the part of the male; each being reciprocally developed in relation to the other. This view now meets with wide acceptance. But we must bear in mind that, for quite a long time, the male is always ready and eager to pair. Such is his disposition while the hormones course in his blood. Not so the female; her readiness, perhaps her eagerness, to pair, comes in periodic gushes, and is possibly correlated with the liberation of internal secretions when the ova"are dehisced from the ovary. If this be so-if sexual excitement in the female be periodic-this must be taken into consideration. If, for example, for every ten times the always-eager male approaches his mate, only once is she physiologically attuned, and psychologically inclined, to receive his 'addresses,' we should call her cold or coy on the predominant evidence of the nine occasions though she may be extremely ardent on the tenth. I am disposed to believe that such

$$
{ }^{1} \text { p. } 330 . \quad{ }^{2} \text { p. } 561 . \quad 3 \text { p. } 342 .
$$


evidence as we have is in favour of this view. But it may here be asked: If this be so, wherein lies the biological value of the persistent ardour of the male? In reply it may be said that, on the basis of general considerations, it seems advantageous that one of the partners should be ready at all times during the pairing season. For if each were ready only on some tenth occasion, pairing would depend on the chance coincidence of this tenth occasion in both sexes. But, it may still be said, if the so-called preference of the female mainly depends on her physiological state at the time, will she not then pair with any eager male that chances to be at hand? When the pairing hunger is insistent, will it not be satisfied by union with this mate as readily as by that? Perhaps in many cases this is so. The evidence alone can decide. In seasonally monogamous species, only her already 'chosen' mate is at hand-though if he be killed a successor is soon in evidence. But, to follow up the hunger analogy, does it follow that because hunger is a condition of taking food, the hungry animal will eat anything? Surely notwithstanding the presence of hunger, there may be, and commonly is, some 'preference' for this over that. May we not say that although a certain internal state (disposition) is a factor in every instinctive response, there is also required an adequate incentive to that response? Is it therefore unreasonable to suppose that even when the wave of pairing sex-hunger comes over the female, the 'display' of this male may, in some cases at least, afford an adequate expression, while the 'advances' of that male do not? If this supposition be justified by the evidence, then, in such cases, there is sexual selection. We must however remember that, if there be a process of sexual selection in intimate relation to other forms of natural selection, the outcome of its continuance for many generations would be to keep the expressional display of the male up to the level, or within a definite range, of adequacy. We do not meet with many failures under other forms of natural selection, just because such failures are so steadily eliminated. Ought we to expect to meet with many cases of lack of adequacy to afford the adequate impression for eliciting the pairing response? Their very absence may be a sign of the stringency of a selective process.

12.

I quite realise that some objection may be raised to my use of the word 'expression.' Why limit it to that which is correlative to impression? Well, why not, for the purpose in hand, if it serves to elucidate a point of view? That point of view is that what I have called impression 
is psychical in its nature, a way in which the bird or other organism is conscious, in the broad sense of this word; and that if expression is (under definition) correlative to impression, then there is a valid sense in which it may be said that the genesis of expression depends on-or, if it be preferred, has been evolved for the sake of-the impression it produces. If this be so, the importance of psychical selection receives due emphasis.

Part of my aim has been to show the intimate connexion of biological and psychological values though the latter are, in the cases discussed, at an early stage of their development. I wish to protest against an undue sundering of natural and psychical selection. Why should not both be regarded as fundamentally natural, our object being to correlate diverse aspects of that which is found in the given nature of one reality? This does not of course preclude the drawing of distinctions. In psychical selection there is preferential appeal of the best expression; under other forms of natural selection there is differential weeding out, the incidence of which falls initially on the worst individuals-those which are bionomically deficient. Psychical selection works from above downwards; natural elimination works from below upwards. But the net result in either case is the preservation of efficiency.

Apart from this it is, I think, only under a misapprehension that sexual selection is regarded as an alternative to natural selection. It is in truth a differentiated form of natural selection, dependent, according to Darwin on exclusive relation to reproduction. Darwin does, indeed, contrast sexual and natural selection, qualifying the latter, in one passage ${ }^{1}$ by speaking of "ordinary or natural selection." But one is not, I think, departing from the spirit of his teaching, if one speaks of sexual selection as a differentiated form of natural selection. Let us assume, then, that sexual selection is analytically distinguishable from other forms of natural selection in and through its exclusive relation to reproduction; and that under the heading of sexual selection two sections may be distinguished; $(a)$ that which includes those modes of elimination that do not involve what $I$ have called the relation of expression to impression; (b) that which includes those modes of selection which do involve, in some form, this relation. And let us go a step further, and distinguish, under (b), two sub-sections; $(a)$ that which includes those modes of expression and impression that are only indirectly related to the pairing act, which we may speak of, in monogamous species, as 1 p. 349. 
securing a mate; $(\beta)$ that which includes those that are directly related to the pairing act. We then have the following scheme under which we may conveniently classify the observed phenomena.
Natural Selection
(a) Not impressional

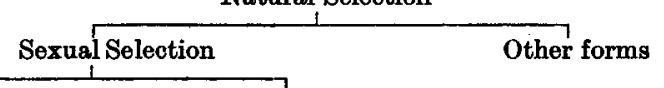
(a) Conducive to mating
(b) Impressional
$(\beta)$ Conducive to the pairing act

(Manuscript received 31 October 1920.) 